\title{
Performances Evaluation at Damaged VIBRATION ISOLATION DEVICES
}

\author{
Nastac, S.
}

Abstract: Based on the structural behaviour influences of dynamic actions, and according to the structural vibration with their parameters modifications under dynamic loads, it could be estimate which, where and how will be the effect quantification of the damages generated by the external loads on a structure. In this paper it was described a variant of response equalisation method, combined with experimental tests, according to, it will be evaluate the demotion degree of a certain system which acquire damages due to the external loads such as vibrations. Basics of this study consists of the stiffness and dampings modifications at one time with structural fatigue, and these modifications leads to a sensible changes of the vibration measured on a structure.

Key words: Vibration, Isolation, Damage, Performance, Identification
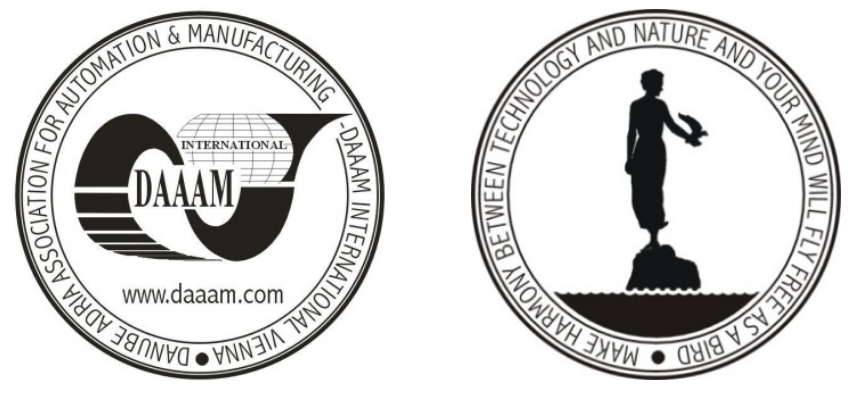

Authors' data: Dr. Nastac, S[ilviu], University Dunarea de Jos of Galati Romania, Calea Calarasilor 29, 810017, Braila, RO, snastac@ugal.ro

This Publication has to be referred as: Nastac, S[ilviu] (2008). Performances Evaluation at Damaged Vibration Isolation Devices, Chapter 47 in DAAAM International Scientific Book 2008, pp.551-564, B. Katalinic (Ed.), Published by DAAAM International, ISBN 978-3-901509-66-7, ISSN 1726-9687, Vienna, Austria DOI: $10.2507 /$ daaam.scibook.2008.47 